\title{
Oxazepam Measurement
}

National Cancer Institute

\section{Source}

National Cancer Institute. Oxazepam Measurement. NCI Thesaurus. Code C75375.

The determination of the amount of oxazepam present in a sample. 